\title{
Harmony in diversity: an empirical study of harmonious co-existence in the multi-ethnic culture of Qinghai
}

\author{
Dorjie Banban
}

Received: 19 April 2018 /Accepted: 25 April 2018 / Published online: 23 May 2018

(C) The Author(s). 2018 Open Access This article is distributed under the terms of the Creative Commons Attribution 4.0 International License (http://creativecommons.org/licenses/by/4.0/), which permits unrestricted use, distribution, and reproduction in any medium, provided you give appropriate credit to the original author(s) and the source, provide a link to the Creative Commons license, and indicate if changes were made.

\begin{abstract}
Finding the key to achieving harmonious co-existence among ethnic groups with different cultural traditions in a multi-ethnic state is a major problem worldwide. Qinghai is located at the intersection of the four major spheres of cultural influence of the nationalities of the Central Plains, Tibet, the Western Regions, and the Northern Grasslands, where multiple cultures co-exist, borrow from each other, seek common ground while reserving differences, thus vividly embodying the coexistence principle of "harmony in diversity." Based on case studies on the Tibetanisation of the Han nationality, the acculturation towards Tibetan culture and Han culture, and the Islamisation of the Tibetanised Hui people in Qinghai, this paper discusses the connotation of "harmony in diversity" in the context of ethnic relations in Qinghai. The author believes that here the "diversity" indicates that every ethnic group has a stable identity related to its own ethnicity, as well as its important cultural traits, and that this identity is fully respected. What is embodied by "harmony" are the feelings of cultural tolerance and cultural sharing, which include different faith systems and cultural traditions, and peacefully coexisting in the same social space. All ethnic groups have multiple identities, mechanisms to rationally resolve conflicts, and so on. This paper explores the conditions of "harmony in diversity" in the multi-ethnic culture formed in Qinghai, and the significance of the Qinghai experience.
\end{abstract}

D. Banban ( $₫)$

School of Philosophy and Religions, Minzu University of China, 27\# zhongguancunnandajie, haidian district, Beijing 100081, China

e-mail: angeleus@sina.com 
Keywords Harmony in diversity · Ethnic identity · Acculturation, ethnic relations

\section{Introduction}

In today's world there is an abundance of instances showing that ethnic issues can become key factors influencing domestic and even international politics. How ethnic groups with different cultures can live in harmony in a multi-ethnic state is an issue of global importance. In this respect, China has accumulated rich theoretical and practical experiences from which to borrow. "Harmony in diversity" is an important part of this theoretical and practical experience.

Confucius said, "A gentleman gets along with others, but does not necessarily agree with them." This suggests that a gentleman should try to achieve harmony even in disagreement, implying that one should acknowledge differences, but also work towards harmony and balance by "adding what is missing and reducing what is in excess." Fei Xiaotong introduced with great insight the notion of "harmony in diversity" in ethnic relations, pointing out that between the civilisations of nationalities it is necessary to "accept the beauty of your own civilisation, and accept the beauties of other civilisations; share all the beauties and create a harmonious world" (Xiaotong 2005). Feng Youlan used the philosophical theory of "harmony in diversity" to review and look into the trends and results of the cultural developments of nationalities in different states: "In ancient Chinese philosophy, 'harmony' and 'commonality' did not have the same meanings. 'Commonality' could not contain 'differences'; not only could 'harmony' contain 'differences', but it needed 'difference' in order to be called 'harmony.' [...] 'That enmity could be dissolved in harmony' is objective dialectics, regardless of people's desires, and contemporary society, especially the international community, developed according to this objective dialectics" (Youlan 1999). Feng also looked forward to the possibility of the history and culture of each nationality getting to a point where "the commonality does not hamper the differences, and the differences do not harm the commonality; all colors shine upon each other, bringing out the best in each other; all instruments play together, bringing harmony and peace; there are different paths that will not go against each other, and all things live together without harming each other; the small virtue flows, and the great virtue becomes sincere; in this way, heaven and earth will become great."

Many philosophers have already discussed the implications of the theory of "harmony in diversity", although we rarely see somebody investigating and discussing its connotations on an empirical level based on the practice of coexistence of multi-ethnic cultures. This study aims at filling in this gap.

We are going to look at Qinghai through the lenses of anthropology and philosophy.

Qinghai has very distinct geographical and cultural features. It is located at the intersection of the Qinghai-Tibetan plateau and the Loess plateau, bordering with the Western Regions and the Northern Grasslands to the North. Being situated at the confluence of four major cultural spheres, those of the ethnic groups of the Central Plains, Tibet, the Western Regions, and the Northern Grasslands, namely, 
the Han culture from the Central Plains, the Islamic culture of the Western Regions, the nomadic culture of the Mongolian plateau, and the Tibetan culture of the Qinghai-Tibetan plateau have collided and blended together for a long time in this region. Here we find all sorts of cultural types permeating and acculturating ${ }^{1}$ each other, forming vibrant genetic relations of ethnic cultures, in which "you are inseparable from me, and I am inseparable from you; there is something of me in you, and something of you in me, to the point that I am you and you are me." These relations vividly embody the coexistence principles of "multiple others," "the union of causes and conditions," and "harmony in diversity" in a multi-ethnic culture.

The author plans to discuss the specific connotations of "harmony in diversity" in relation to the coexistence of multi-ethnic cultures, on the basis of empirical data gathered on the interdependence of different nationalities in Qinghai which use each other's strengths, mutually benefit from each other, and culturally borrow from, intersect, and seek common grounds from each other while maintaining their differences. By doing so the author hopes to contribute to the understanding of how different nationalities within a multi-ethnic state can coexist peacefully, and cooperate and develop in harmony.

\section{Methodology and data collection}

\section{The five dimensions of our investigation}

The prominent feature of multi-ethnic culture in Qinghai is that extensive acculturation has occurred in the context of ethnic coexistence. In order to investigate the phenomenon of one ethnic group absorbing cultural elements from another, as well as how this changes group members' psychology, what dimension should we observe? We know that nationality "indicates a stable community with a shared language, shared geographical region, shared economic life, which is formed by human beings at a certain stage of historical development, and common psychological qualities that are expressed in shared ethnic cultural traits". According to this, based on the characteristics of the multi-ethnic acculturation of Qinghai, we have determined that ethnic culture and its attached ethnic identity should be a main point of our investigation. ${ }^{2}$ So, what are other points we shoud take into consideration within ethnic culture? In 1871, British anthropologist E. B. Tylor formulated the following classic definition of culture: Culture or civilization, taken in its wide ethnographic sense, is that complex whole which includes knowledge, belief, art, morals, law, custom, and any other capabilities and habits acquired by man as a member of society. Based on Tylor's definition, combining the concrete circumstances of ethnic cultures in Qinghai that mutually absorb and borrow from each

\footnotetext{
${ }^{1}$ The phenomenon of acculturation happens when two or more cultural systems are continuously and directly in contact with and influence each other, causing one or both sides to experience cultural variations on a large scale.

${ }^{2}$ In the past scholars have discussed at lengths about the content of shared psychological qualities. Nowadays there is a consensus that ethnic identity is the most important component of ethnic psychological qualities.
} 
other, this paper highlights five dimensions to analyse the circumstances of acculturation of every ethnic culture. The five dimensions are: 1) language; 2) religion; 3) marriage; 4) ways of life; 5) ethnic identity.

\section{Documentary research and case studies}

By analysing historical documents and case studies, this paper aims to investigate the cultural borrowings that occurred between different ethnicities in Qinghai throughout the long course of historical contact, and how ethnic cultures have changed because of that. Therefore, we are going to consult relevant documents, while also conducting fieldwork.

In accordance with this paper's objectives, we have chosen six cases of cultural borrowings in Qinghai as prominent case studies: the Tibetanisation of the Han in the Ningba village of Daowei Tibetan township of Xunhua county, Haidong prefecture; two cases of acculturation towards Tibetan culture; two cases of acculturation towards Han culture; and the Islamisation of the local Tibetan Huis in Kaligang, Hualong county, Haidong prefecture. Here "the acculturation towards Tibetan culture" and "the acculturation towards Han culture" refer to an ethnicity borrowing multiple elements from another culture, without however being assimilated into the ethnicity lending said cultural elements, but retaining the major features of the original ethnic group.

From July to October 2006, members of our research team conducted fieldwork in the aforementioned six sites. In the following section we will give a basic outline of the six cases, and then discuss them in detail.

Primary research outcome: The six case studies

\section{Tibetanised Han people: The Daowei Ningba model ${ }^{3}$}

There are many instances of Tibetanisation of Han people in Qinghai, however the degree of Tibetanisation tends to differ. In the Hehuang region ${ }^{4}$ cohabitated by both Han and Tibetans, we can easily see how Han families that lived in Tibetan areas for two or three generations have been fundamentally Tibetanised.

We chose to look at the Tibetanisation of the Han people living in Ningba village, in Daowei Tibetan township of Xunhua county, Haidong prefecture for one of our case studies. The Han population of Ningba consists of the descendants of a carpenter and a peddler who arrived there in the 1940s from Linxia prefecture

\footnotetext{
${ }^{3}$ This case study was carried out in August 2006 by Li Guo, member of our research team and graduate student of Ningba Tibetan ethnicity at our university's School of Tibetan Studies.

${ }^{4}$ The "Hehuang" region includes today's Haidong prefecture, centered around Xining, Huangnan Tibetan autonomous prefecture, Hainan Tibetan autonomous prefecture, Menyuan Hui autonomous county inside Haibei Tibetan autonomous prefecture in Qinghai province, as well as Linxia Hui autonomous prefecture, and Xiahe county in Gannan Tibetan autonomous prefecture in Gansu province. Fei Xiaotong called the Hehuang territory a "point of connection between the Central Plains and the Qinghai-Tibetan Plateau."
} 
of Gansu to make a living. The main nationality of Daowei township is Tibetan, constituting over $80 \%$ of its population, while the Han represent approximately $15 \%$. Under the long-term influence of Tibetan culture, the Han portion of the population became fundamentally Tibetanised, in terms of faith, cultural attitudes, ideological tendencies, lifestyle, and so on. Ningba represents a village where Han and Tibetans naturally mingle. In the entire village there currently are over 180 households and more than 1000 people, among whom 169 households (940 people) are Tibetan, constituting $90 \%$ of the village's total population: Tibetans are this village's original inhabitants. There are 11 Han households, consisting of 60 individuals, which is $10 \%$ of the population. In the village there is a Gelugpa temple and a Mani kang, and the entirety of the village's population practices Tibetan Buddhism. Before the foundation of the People's Republic of China, Ningba village mostly relied on the raising of livestock, while afterwards it gradually abandoned livestock breeding in favour of agriculture.

What makes Tibetanised Han people unique is that in order to survive they consciously and actively integrated with the Tibetan population. They converted to Tibetan Buddhism, they started behaving according to the same rules and conventions as Tibetans and speaking their language, they married Tibetans and celebrated their weddings in accordance with Tibetan customs, gave their children Tibetan names, studied the Tibetan script, and addressed their family members with traditional Tibetan appellatives. This model is an example of classic "selective acculturation." This kind of acculturation model is often realised through interpersonal amicable contacts, therefore the process of de-sinicisation was rather fast, occurring in only two generations, since the grandchildren no longer speak Chinese. The lifestyle of these Han people is no different from that of Tibetans, having been basically Tibetanised. They consider themselves to be Tibetanised Han, and also the local Tibetan population sees them as Tibetans. It is interesting to see that some of those Han families send their children to Tibetan schools to study the Tibetan language, and a portion of them goes on to specialise in Tibetan language and literature in universities such as Northwest University for Nationalities, and after graduation they work as Tibetan language teachers. All of this implies that the process of identification as Tibetans is in fact a process of internalisation of Tibetan cultural rules.

Nonetheless, in important life rituals they still maintain elements of Han culture. For example, they preserve the traditional Han burial customs, believing that cremation or sky burials are disrespectful towards the dead. Furthermore, during the Spring Festival they apply traditional couplets and images of door gods to their doors, they offer sacrifices to their ancestors on Tomb-sweeping Day, and so on.

Acculturation goes both ways. In the Hehuang region and even in the nearby half-farming half-herding areas, Tibetans have also, to a certain degree, absorbed several cultural factors from the Han population. These Tibetan people can usually speak the local Han dialect, and some are even proficient in the Chinese written language; many of them have Han names and celebrate Han festivities. It is in fact difficult to tell Han and Tibetan people apart. Still, in these areas, regardless of whether they are Han, Tibetan or belong to another ethnic group, they always have a very clear understanding of what their ethnic identity is. These examples illustrate how, within the amalgamation of the Han and Tibetan nationalities, religious and 
cultural identity can be mutually infiltrated, whereas ethnic identity is a hard core, impossible to penetrate, and not easily changed.

\section{Two cases of acculturation towards Tibetan culture ${ }^{5}$}

The Mongolian model in He'nan: The acculturation of the Mongols towards Tibetan culture The He'nan Mongolian autonomous county, in Huangnan Tibetan autonomous prefecture, Qinghai province, is located in Southern Qinghai, bordering with Zeku county in Qinghai to the North, Sichuan's Aba Tibetan and Qiang autonomous prefecture to the South, and Gansu's Gannan Tibetan autonomous prefecture to the East. It is enclosed in a ring of Tibetan culture. According to statistics from 2000, the Mongolian population of this county represented $89.55 \%$ of the total population of the county, which happens to be the only Mongolian autonomous county in Qinghai. The Mongols who live there arrived in different tribes, in different time periods. Their ancestors were mainly Mongols belonging to the Heshuote and Tu'erhute tribes from the Erlute tribe, and Dawu'er and Huoluochi tribes from the Tumote tribe in the desert. ${ }^{6}$

The first Mongolians arrived in that area in the thirteenth century, during the Southern Song dynasty. Due to being surrounded by Tibetan culture and in the course of interacting and mixing with the Tibetans over a long period of time, they experienced deep acculturation towards Tibetan culture in terms of religious beliefs, value orientation, ways of thinking, esthetic inclination, social customs and practices, spoken and written language, and so on. They spoke a refined, standard Tibetan from the Amdo pastures ${ }^{7}$ and converted to Tibetan Buddhism. Several centuries later, they still "enjoy plentiful food, wear beautiful clothes, live in the safety of their homes and carry out their own customs" in this geographical and cultural environment, and have given up further migration.

\footnotetext{
${ }^{5}$ The research for these two case studies was performed by the author together with Dr. Suo Duanzhi, member of the research team and professor at Qinghai Nationalities University.

${ }^{6}$ According to historical records, the Mongols from He'nan County arrived at the foot of Xiqing Mountain, south of the Yellow River, from three directions and in different time periods. As early as 1257 (fifth year of Baoyou's reign in the Southern Song dynasty), when the Mongolian army attacked the Southern Song, it established relay stations (Ayibo and Shuchi) and horse ranches in today's Maqu county in Qinghai, Nuo'ergai county in Sichuan, and in the southern part of He'nan county in Qinghai, in order to safeguard the rear contingent of caravans transporting military material. Afterwards, some of their people settled down there, becoming the earliest group of Mongolians south of the Yellow River. In 1588, (16th year of the reign of Wanli), Huolachi, the chief of a tribe from the southern desert, arrived at Niegongchuan (today's region of Tongren and Zeku counties): this was the second time that Mongolian people entered the area south of the river. In late autumn 1636 (9th year of the reign of Chongzhen), following the rules of the Gelugpa school of Buddhism, 10,000 men led by Gu Shihan's troops marched towards Qinghai,and settled in the grasslands there. The majority of He'nan county were Elute Mongolians, who arrived in Hequ area in 1652 (9th year of the reign of Sunzhi). From Cai Rang, ed., A History of the Mongols in Qinghai), Qinghai People's Publishing House, 2006, p.1-11.

${ }^{7} \mathrm{~A}$ cadre of Mongolian ethnicity in He'nan county jokingly told us, "One hundred percent of Mongolians speak Tibetan $100 \%$ [of the time], and it is a hundred percent guaranteed that a hundred percent of Mongolians cannot speak Mongolian. This is how things are for us Mongolians in He'nan county."
} 
Even though the Mongolians living in He'nan Mongolian county are aligned with the Tibetans in terms of cultural and religious identity to the point that they are essentially one in those respects, their ethnic identities present differences:

Firstly, the common people identify themselves as either Mongolian or Tibetan, the cadres identify as Mongolian, with some grassroots level cadres having a very strong sense of identity as Mongolians. In this model of selective Tibetanisation, on the one hand, the degree of acculturation and Tibetanisation of Mongolians is considerably high. However, on the other hand, the surrounding Tibetan society has great influence, and there is no doubt that it subjects them to a form of intangible pressure. This is another very common counter-reaction phenomenon in the process of selective Tibetanisation..

Secondly, numerous cadres and teachers also identify with the Tibetan nationality, but this identity is not as strong as their Mongolian identity. Nonetheless, they still maintain a great quantity of Mongolian cultural characteristics: in terms of lifestyle, they preserve numerous Mongolian traits, in terms of ethnic consciousness, they want to promote the teaching of the Mongolian language in primary schools with a Mongolian language foundation. However, studying Mongolian has little practical application, and those teachers have gradually changed professions. As a result, they decided to reinstate Tibetan language as the main subject, and Chinese as a subsidiary course, although it is still possible to also take a Mongolian course. ${ }^{8}$ This is a type of acculturation in which Tibetan culture is oriented towards high-level of Tibetanisation while still preserving the Mongolian ethnic identity.

\section{Upper and lower Wutun: The acculturation of the Tu ethnic group towards Tibetan} culture The Tu nationality in the community of the Upper and Lower Wutun in Tongren county in Huangnan Tibetan autonomous prefecture, Qinghai, are famous worldwide for their devotion to Tibetan Buddhism and the creation of Buddhist thangka and statues. "Wutun Art" is a famous style of Tibetan Buddhist art and Wutun has become home to a nativized aspect of Tibetan culture.

In terms of ethnic identity, the inhabitants of Wutun present interesting Tibetan orientations. In the 1950 s, their ethnicity was ascertained to be Tu; by examining a great quantity of documents, we can see that they were originally Han immigrants, and also had Mongolian components: however, they identified themselves as Tibetan.

This is the situation with regards to ethnic identity being Tibetan: 1) oral history reports that their ancestors were originally Tibetan, and the legends have it that they were Tubo people dispatched to the Tongren border garrison from the Yalong valley during the Tibetan Tubo Dynasty; 2) selective ethnic identity: considering oneself to be Tibetan is beneficial. ${ }^{9}$ This is a choice that is made based on what Weber called "instrumental rationality." Presently, many of the elderly members of

\footnotetext{
${ }^{8}$ A Mongolian author in He'nan county told us, "We all have the ethnicity complex of Mongolians, but ethnic feelings won't feed you, it is still important to face reality, solve real problems, which is our attitude towards our ethnic responsibility."

${ }^{9} \mathrm{We}$ interviewed one member of the management of the temple in Wutun, and when the interviewer asked him: "The government has recognized you as Tu people, and you had your own language and clothing, why did you want to change to Tibetan people?" His reply was: "What's good about being Tu people? At least as Tibetans we are respected by people."
} 
this group are still registered as being of Tu nationality because this was determined through the national administrative and institutional approval of nationalities during the 1950s ethnic identification work and cannot be changed, even though numerous younger inhabitants of Wutun subsequently chose to be officially recognized as Tibetan; 3) psychological basis: they lived for a long time surrounded by Tibetans and Tibetan culture, almost entirely accepting Tibetan Buddhism and Tibetan culture, and this formed the psychological basis for them to identify themselves as Tibetan. These few points illustrate how in certain times, ethnic identity can be chosen, and it is more about how people identify themselves in terms of culture, religion, customs, value orientation and behaviours.

To summarise, between consanguinity and cultural ethnic identity, the Mongolians in Henan chose the former, while the inhabitants of Wutun the latter. These two models also happen to correspond to the five dimensions of our analysis framework.

\section{The two cases of Han acculturation of the Tibetan nationality}

The Zhuocang model: Setting boundaries without closing the doors ${ }^{10}$ Since the Zhuocang Tibetan minority inhabited the Hehuang region during the Ming dynasty, they coexisted with Han, Hui, Tu and Mongols. With their open and inclusive attitude, they learned how to speak and write Chinese, and took on Han social customs and habits. Ledu county, where Zhuocang is situated, is located in the Hehuang region, where it was very easy for Qinghai Tibetans to absorb Han culture. The level of Chinese, as well as the Han cultural factors adopted by Zhuocang Tibetans are very high compared to the rest of Tibetans in Qinghai and even Tibetans nationwide. Before the founding of the People's Republic of China, the people of this region studied the Four Books and the Five Classics, and some of the widely known Han stories about Xue Rengui and the Romance of the Three Kingdoms circulated here. Conversely, while borrowing many elements from mainstream Han culture, they always maintained the dominant status of Tibetan Buddhism and Tibetan culture, meaning that they still mainly used cultural elements of their own ethnicity. Zhuocang is also an area within the Hehuang region, in Qinghai, where Tibetan language and social customs are still relatively intact.

i. i.Numerous linguistic elements assimilated from Chinese. Since ancient times until now, the Zhuocang Tibetans have spoken Tibetan, however, they have borrowed a great number of words from Chinese. In the course of ten sentences, they will mix in three or four Chinese words; some of the keywords in Tibetan are in fact Chinese words.

ii. Taking on Chinese surnames. The Tibetans living in the Zhuocang region usually have Chinese surnames. Preliminary statistics show that the Zhuocang Tibetans have approximately 50 Chinese surnames, including Mei,

\footnotetext{
${ }^{10}$ This case study was completed in September 2006 by Dr. Zha Luo, a Zhuocang member of our research team and associate researcher of the Institute of Ethnology and Anthropology of the Chinese Academy of Social Sciences.
} 
Su, Xiang, Bai, Bao, Qi, and Qian, however, their given names are Tibetan, such as Fanjiayang or Licaidan. Han surnames and Tibetan names have become complementary, blending together in harmony. At the same time, they still maintain their own Tibetan family names (Hangxiudongzhu and Shangmajie 2002a). When they communicate with the outside world, they use their Chinese last names, and while they are among themselves they use their Tibetan family names, forming a double-track Chinese-Tibetan naming system.

iii. Learning Han life techniques. Founded upon intensive farming, the Han culture was more refined and advanced in terms of life techniques. The Zhuocang Tibetans learnt from the Han the arts and technology of dressmaking, embroidery, and shoemaking. On the other hand, while opening the door for the study of Han culture, the Zhuocang Tibetans also held on to the foundations of their own Tibetan culture.

First of all, they continued using Tibetan language. Secondly, they believed in Tibetan Buddhism and followed its religious practices, such as using prayer beads and burning incense to worship Buddha. Thirdly, they preserved their own social customs and practices, as well as their traditional values. They wore fur-lined coats, while women wore jialang, they ate tsamba (roasted barley meal) with butter, and they raised livestock. With respect to their ethnic spirit, they valued courage, honesty and diligence, the hungry did not beg for food, the poor did not steal, the rich did not abuse the poor, martial arts were highly regarded, and dying of illness was considered a disgrace, while dying in battle was seen as honorable (Hangxiudongzhu and Shangmajie 2002b). Fourthly, they attached extreme importance to the purity of the Tibetan lineage, and they maintained the practice of intermarriage within the ethnic group.

Now, these standards still have great binding power on the members of this ethnic group, and are used to guide and control their marriage activities. On the one hand the Zhuocang Tibetans have an extremely open attitude towards different cultures, yet, on the other, they scrupulously adhere to their own core culture, maintaining a type of attitude that sets boundaries without closing doors.

The "Jiaxifan" model: Deep acculturation of the Tibetan nationality towards Han culture $^{11}$ "Jiaxifan" is the name designated for those Tibetans in the communities surrounding Kumbum and the Hehuang region who have already been deeply Sinicised and suggests they are "neither Tibetan nor Han." According to New Qinghai: Local Annals, Vol. 2, No. 11, "The Shenzhong 13 families, apart from the Qunjia people, the Jia'erzang and Suo'erjia Tibetans that are partially not Sinicised, have been completely assimilated into the Han population." The Shenzhong 13 families consists of six tribes in Kumbum. These Tibetans who have been assimilated into the Han population are in fact the "Jiaxifan." The degree of Sinicisation of the "Jiaxifan" is deeper in comparison to the Zhuocang Tibetans. Historically the "Jiaxifan" were Zongka Tibetans, and between the Yuan and the

\footnotetext{
${ }^{11}$ This case study was carried out by Professor Xian Ba, member of our research team, native of the Kumbum region in Huangzhong, and Professor at Qinghai Nationalities University.
} 
Ming dynasties they were basically part of a nomadic ethnic group, "raising animals, living by the water and without a fixed place to stay." Starting from the mid-Ming dynasty, with the implementation of the "migrating people to border places" policy, a great number of Han people migrated to the Hehuang region, where they lived together with the local non-Han people either in garrisons or in villages. Their production methods gradually changed, and according to the New Record for Xining Prefecture, the Shenzhong and the Xina ethnic groups "had cities with walls, huts and small buildings, and their economy was based on agriculture and livestock breeding." After several centuries of contact and exchange, by the mid-Qing dynasty, their production methods had completed the transition from nomadic pastoralism to farming, and agriculture had become their main mode of production.

The large-scale movements of Han people not only introduced agricultural production to the region, but also caused the cultural system of the local people to undergo structural changes so that Han culture became the mainstream secular culture for the majority of the Zongka Tibetans. They were eventually called "Jiaxifan," because they were essentially Sinicised in terms of outside features of ethnic boundaries, such as diet, architecture, and clothing. Linguistically speaking they lost their mother tongue - Tibetan language - and Han language was used both inside their households as well as for external social interactions. They also generally adopted Chinese names. In terms of marriage, the boundaries of marriage within the ethnic group were loosened, and they started to allow intermarriage with other ethnic groups. This was perhaps the fundamental reason why those living in the area around Kumbum who originally were Tibetans became Jiaxifan. The conditions of the Zhoucang people and the Jiaxifan people amply illustrate that "Marriage within the ethnic group and intermarriage with other ethnic groups was an important variable in preserving ethnic stability and causing ethnic changes" (Kongs hao 2005). However, their ethnic identity was Tibetan, and they still believed in Tibetan Buddhism, even though the degree of consciousness and belief in their own ethnic group was no longer strong.

Throughout the three decades of the PRC's Reform and Opening-up, this phenomenon underwent some changes, and a sort of "atavism" appeared among the Jiaxifan people. Between July and August 2006, the research conducted by members of our research team on Baiya village in Lanlongkou town and the Upper and Lower village in Upper Xinzhuang town, in the area of Kumbum, indicated that apart from a small number of elderly people, the majority of the Tibetan population of these villages could not speak Tibetan, even though they all had Tibetan names. At the same time, those cultural traits with Tibetan features, such as marriage, dress, language, names, architecture, diet, and transportation started to reflect Tibetan culture. People started wearing Tibetan clothing, celebrating Tibetan holidays, going to Tibetan Buddhist temples to burn incense during the Chinese New Year, and so on. Several communities restored the long-lost custom of practicing Tibetan dances. In the past few years, places such as Upper Xinzhuang town, Gonghe town, and Suo'erjia village in Danma township established five dancing teams, and during the celebration of the Chinese New Year and other festivals they wear Tibetan clothing, sing modern Tibetan songs in performances in each community. In recent years Gonghe town also 
restored traditional horseback-riding competitions. This reflects the "cultural self-awareness" of the Jiaxifan people amongst global economic and cultural trends.

While investigating Lanlongkou town, the one with the highest degree of Sinicisation among the six tribes in Kumbum, we also realised that people in a normal context still come across the phenomenon of seeking conformity and distinguishing whether "someone is Tibetan" or "someone is Han." This shows that when it comes to the relationship between the self and the other, stable ethnic boundaries and identity have been established. This phenomenon, in which there are differences among the similarities, and similarities among the differences, is manifested with an "inverted pagoda" shape in the ethnic relationship in places like Huangzhong county, in Qinghai. From Xining to the north of Kumbum, the customs of Tibetan people in townships such as Duoba and Lanlongkou, including names, clothing, marriage, and language, are completely Sinicised, but though the psychological boundaries in their mindset of "I am Tibetan, I am different from a Chinese" are not clear, they still exist. To the south of Kumbum, the names, clothing, language, wedding traditions of Tibetans living in the Laji Mountains, such as Zhangfangtai and Jia'erzang, are a mix of Tibetan and Chinese social customs: Chinese language has a more prominent role, but they also speak Tibetan, and the psychological boundaries in thinking "I am Tibetan" are very clear-cut. Tibetans living outside of the Laji Mountains, such as Qunjia Tibetan township, live together with Chinese, and their names, clothing, language and marriage traditions have entirely maintained their Tibetan features and traits. The main language is Tibetan, but they also speak Chinese, and have borrowed from the customs and faiths of the Han people. For example, they believe in Daoist Wenchang deity, they celebrate Han festivities like the Spring Festival and the Dragon Boat Festival. This is the "inverted pagoda model" of acculturation line that characterises the interactions and amalgamation between Tibetan and Han culture in the area from Xining, to Kumbum, through the Laji Mountains and to Qunjia, a long and complex natural historical process.

Religion plays an important role in ethnic identity. Here there is a Buddhist and Bonist mixed faith system formed by the religious ceremonial places in Kumbum temple, Xina temple, and village temples (or mountain temples) ${ }^{12}$; the Tibetans living there are extremely devout, and conscientiously practice a complex system of traditional religious ceremonies. Obviously, the reason why the Jiaxifan people hold on to their ethnic boundaries, is directly connected with Kumbum monastery. The existence of Kumbum and its system of temples allow the Jiaxifan people to be in harmony within the sea of Han culture without changing, thus preserving their own cultural features.

\footnotetext{
${ }^{12}$ The places where the six Tibetan communities in Kumbum perform religious activities are normally divided into four types: every house has a hall dedicated to worshipping the Buddha, every village has a small temple, or "mani kang," every township has temples, and the mother temple of the six tribes is Kumbum. The religious activities practiced in these places are dominated by Tibetan Buddhism, mixed with elements of the Bonist or Islamic faith. Simply put, Buddhism rules over other-worldly affairs, such as the afterlife or becoming Buddha, while Bonism or Islam rules over their worldly affairs. For instance, divination, funerals et cetera.
} 


\section{The Kaligang model $^{13}$ : The Islamisation of Tibetanised hui}

Kaligang is the phonetic translation from Tibetan, and means "high mountain," or "snowy mountain". The Kaligang region consists of the territories including Dehenglong township, Ashen township and Shabianbao township, in Hualong Hui autonomous county. Members of our research team conducted research in the Deyi and De'er villages of Dehenglong township.

Figuratively speaking, the Tibetanised Hui people in Kaligang represent a community of people who dress in Tibetan clothes and speak Tibetan, but go to the mosque to worship. They have cultural elements from both the Tibetan and the Hui cultures, and looking at them from an ethnic orientation and cultural behaviour orientation, we see that the Tibetan cultural identity is progressively fading away, to the point that in recent years there has been a phenomenon of "de-Tibetanisation," while the Hui cultural identity is growing stronger.

The double Tibetan and hui genetic cultures in Kaligang The Tibetan and Hui cultures in Kaligang are composed by factors of both cultures and both have coexisted for a very long time, becoming gradually influenced by each other, and following the specific circumstances of historical periods, they experienced reciprocal up and down changes. Generally speaking, for a very long time, the religious faith of the inhabitants of Kaligang was Islam, while their secular culture was Tibetan. In the villages of "Tibetanised Hui" we have seen mosques built two, even three centuries ago, and it is worth noting that their architecture absorbed many factors from Tibetan architecture. Furthermore, the imams always use Tibetan, whether they are discussing the Quran or preaching to mosque-goers. The secular life of the Tibetanised Hui in Kaligang is still characterised by traits of Tibetan culture.

The rapid transition of social changes in contemporary China and the culture of "Tibetanised hui" in Kaligang Following the Reform and Opening-up period, the cultural traits of the "Tibetanised Hui" in Kaligang, as well as the self-identity of ethnic groups underwent great changes. In the very brief period of two decades, the Tibetanised Hui became rapidly integrated in the Hui sphere of cultural influence, in terms of ethnic self-identity, an ethnic sense of belonging, ethnic attitude or ethnic involvement.

The factor promoting this process was that the "Tibetanised Hui" in Kaligang left their homes, establishing contact with a wider world. In the past twenty years, those people in Kaligang who were wealthy enough went abroad for the Hajj, and young people went to county or provincial cities, and even the coastal area to work as labourers, to conduct trade or to open restaurants. In the midst of social changes, the social identity of "Tibetanised Hui" of Kaligang, because of their dual cultural characteristics, became inconvenient: "Tibetans see us as Hui, but Hui people consider us not to be legitimate" (from an interview of a villager from De'er, male, 46 years old). That is, the two ethic groups see the "Tibetanised Hui" as not belonging to their own ethnicity, and they see them as unfaithful. Therefore, they

\footnotetext{
${ }^{13}$ This case study was performed by Professor Sang Cairang, member of our research team, native of the Hualong area, and Professor of the Qinghai provincial party school.
} 
felt they only had one option: to choose the Hui ethnicity, because it is impossible to enter the Tibetan cultural sphere while having an Islamic faith. Furthermore, they also feel that the ways of life of the Hui are more reasonable. "The Tibetans lead very hard lives" (from an interview of a villager from Cuozha, male, 55 years old). "Ma Laichi brought good ways of life, the Hui people don't drink and don't smoke" (from an interview of a villager from Deyi, male, 50 years old).

In this context, religion plays a crucial role in the choice between Tibetan and Hui culture. In the mid-1980s, the imam of Kaligang rounded up the men in the mosque, and made a solemn announcement: the people of Kaligang were to strictly adhere to the principles of Islam, and were no longer allowed to behave according to Tibetan social practices. This was the hallmark event of the transformation of the "Tibetanised Hui" in Kaligang. Since then, they consciously emphasised the things they had in common with the Hui people, while stressing the differences with the Tibetan people. The "Tibetanised Hui" in Kaligang quickly reverted to being Hui.

In terms of religion, nowadays the religious atmosphere in Kaligang is extremely strong, and Islam is deeply entrenched in the minds of people living there. The "Tibetanised Hui" are religious and strictly practice religious activities according to the rules of Islam, and every year those who can afford it go to Mecca.

Linguistically speaking, Tibetan is still the main means of communication in this area, however, people have started giving up Tibetan names and taking on Hui names. Even religious words, such as "faida," "bokeh," "Allah," "al-amal," "Mustahabb," and "kelahaiti," are starting to be read in Arabic, with explanation provided in Tibetan.

In their everyday life, the Tibetanised Hui of Kaligang have entirely converted to Hui culture. In the past they would dress with Tibetan clothes, but after the Reform and Opening-up they started wearing Hui garments. ${ }^{14}$ In terms of diet, the "Tibetanised Hui" in Kaligang strictly observe the Muslim restrictions, and they refrain from eating carrion, blood, pork and animals that were not slaughtered in the name of Allah. They do not smoke or drink. While eating, they must hold tableware with their right hand, and they are prohibited from putting their hand behind their back to pour water or serve food. Nowadays it is already very hard to see in the life of "Tibetanised Hui" in Kaligang traces of the Tibetan diet. In their wedding traditions, they strictly maintain their wedding boundaries with surrounding Tibetans, and there are no instances of intermarriage between the two ethnic groups. The wedding customs of Tibetanised Hui have been completely converted to Hui wedding customs. In terms of architecture, after the Reform and Opening-Up period, when building new houses or renovating old ones, they started following Hui patterns, and in some Tibetanised Hui villages vestiges of Tibetan architecture are nowhere to be seen. In their everyday lives, the Tibetanised Hui of Kaligang still have the habit of baking ox manure, but they no longer use the Tibetan method of carrying casks on their back to transport water, and they started using shoulder poles or mules. When it comes to festival culture, the traditional

\footnotetext{
${ }^{14}$ It is important to point out that nowadays the Tibetanised Kaligang people are not the only ones not to wear Tibetan clothes, since apart from when they are celebrating holidays, the Tibetans in Hualong and even the Hehuang territory usually wear modern Han-style clothing.
} 
holidays of Tibetanised Hui in Kaligang are "Eid al-Fitr" and "Eid al-Adha," whereas the traditional Tibetan holiday customs are no longer preserved. When it comes to burial customs, the Kaligang "Tibetanised Hui" bury their dead, and the entire funeral ceremony strictly follows Islamic rules. In the past there also existed the customs of cremation, water burial, and sky burial, however these practices have disappeared.

In terms of cultural recreational activities, today the Tibetanised Hui of Kaligang still sing traditional Tibetan love songs in Tibetan, however, according to Tibetan customs, in the past they would organise horse racing and archery competitions during festivities, but they no longer have this tradition.

All in all, apart from using the Tibetan language, the Kaligang "Tibetanised Hui" have basically experienced a transformation of their value orientation to the Hui ethnic group, in all areas, from secular culture, such as social customs, to the divine world, like their religious belief. This is also part of a relatively representative phenomenon of cultural amalgamation in the theory of acculturation.

\section{Secondary research outcomes: Cultural borrowing and mutual respect}

Culturally speaking, all the ethnic groups in Qinghai have an open attitude, borrowing what they can, and respecting what they are not willing to borrow. In terms of borrowing, since the doctrines of religious systems are very clear-cut, with distinct, easy to discern boundaries. In the following paragraphs we are going to discuss the examples of the mutual borrowing of religious elements.

\section{Borrowing of religious elements}

Qinghai is an area of intersection of multiple cultures, where people believe in a number of religious faiths, such as Bonism, Shamanism, Islam, Chinese Buddhism, Tibetan Buddhism, and Daoism. Some of them were only practiced in the past, while others still exist to this day. Therefore, in Qinghai we can see an interesting phenomenon of a great number of religions being practiced at the same time.

Elements of Tibetan Buddhism in Daoist worship We are first going to look at traits of Tibetan Buddhism in Daoist rituals. During temple fairs in Minhe county in the Hehuang area, the Yin Yang masters carry out Daoist rites from beginning to end, but when they start chanting the sutras, they perform the Tibetan Buddhism ceremony of "rising the banner." The Zhujiamiao temple in Zhongchuan township, Minhe county, is consecrated to the deity of the Sanchuan area in Minhe county, Erlangshen, however, in front of the hall there is a mulberry stove for Tibetan Buddhist worship, and the statue of Erlangshen is wrapped in a khata. This temple is also managed by Tibetan lamas. ${ }^{15}$

There is also an example of Daoist and Tibetan Buddhist ceremonies being performed side by side. In 2006, the patriarch of a Han household living close to Guide county town, held a ceremony for the tenth anniversary of his father's passing, when they invited two or three Yin Yang masters (that is, Daoist priests), as well as five or six Tibetan lamas. The Yin Yang masters performed the memorial service in the Eastern wing according to Daoist rituals, while the lamas chanted 
Buddhist scriptures and performed ceremonies in the Southern wing in accordance with Tibetan Buddhism. Each religion had its own place, and performed its own duty, without interfering with the other.

Daoist elements in Tibetan Buddhism worship In Gansu and Qinghai, it is rather common for Tibetan Buddhism to assimilate elements of Daoism. The Daoist deities Lord Guan and Emperor Wenchang became the objects of adoration of several lama temples. In the early Qing dynasty, Lord Guan was officially inducted into the pantheon of Tibetan Buddhism. In the Amdo region, Tibetans regard Lord Guan as the king of the South of the four heavenly kings, namely the god of wealth in Tibetan Buddhism. Clearly this is connected with the consecration of Lord Guan by the local Han people as the god of wealth. Furthermore, Emperor Wenchang was also introduced into the Tibetan Buddhist pantheon, and in the Tibetan area of Amdo he enjoys a high level of prestige and influence. Emperor Wenchang is called "Ami Yola" in Tibetan, which means local god. The Tibetans believe Emperor Wenchang to be an exceptionally powerful deity, quickly granting whatever he is asked for, making clear distinctions between rewards and punishments, and whose influence surpasses by far that of the aboriginal mountain gods. Tibetans in several places, together with Han people, have also built temples consecrated to Wenchang, called "yola kang" in Tibetan.

Simultaneous worship of Daoism and Tibetan Buddhism In some instances the mutual borrowing between Daoism and Tibetan Buddhism in Gansu and Qinghai resulted in a degree of mutual integration. Nowadays, the temple of Lord Guan in Labrang town, Xiahe county, Gansu, is a small Daoist temple built by local Han people, however it is characterised by a strong combination of features of Daoism and Tibetan Buddhism. Inside this temple, Lord Guan and local mountain deity Ami Nianqin of Southern Gansu are worshipped in the same hall, and there are Tibetan thangkas and statues. It is interesting that the local Han people see Ami Nianqin as a founding figure of the Ming dynasty Xu Da (also called Hu Dahai), and they say that in the past he was revered as the god of the Taizi mountains. However, the statues of Ami Nianqin have a classic Tibetan Buddhist style, having been sculpted by Tibetan artists. Inside the temple of Lord Guan there is a harmonious combination of Han and Tibetan elements: in the pavilion there is a mulberry stove, and there is a khata wrapped around Lord Guan's statue (Rang 1999). In short, in the temple of Lord Guan two deities from two different faith systems are worshipped together by the local Han and Tibetan people. This is a typical example of the simultaneous worship of Daoism and Tibetan Buddhism in a way that incorporates elements from both religions.

The mix of ancient and modern Han and Tibetan cultures In Qinghai, where Han and Tibetan cultures coexist, we often see interesting phenomena that ancient and modern Han and Tibetan cultures are mixed together. For example, in the houses

\footnotetext{
${ }^{15}$ This case study was carried out by Ma Jingjie, member of our research team and graduate student in the School of Philosophy and Religion of our university.
} 
of the Jiaxifan people in Su village, close to Kumbum, in addition to the images of Buddhist saints, like master Tsongkhapa, there often are portraits of Chairman Mao, pictures of the god of longevity, traditional Chinese landscape paintings, and so on. When celebrating the Spring Festival, the Jiaxifan people also attach couplets on their doors, set off firecrackers, and also take part in the village's celebrations, with lion dances, Tibetan dances, and performances on stilts, which animate the village's alleys for several days. The Jiaxifan people also offer sacrifices to the gods, even though they do so one night before the Han people.

\section{Mutual respect between ethnicities}

Different ethnic groups willingly borrow from each other's culture, which is already a commendable instance of "accepting the beauty of other people." But how do different ethnicities treat those parts that are not reciprocally borrowed? In the process of multiple cultures coexisting and colliding over a long period of time, what sort of principle of amicable interactions did they come up with?

The experience of Qinghai shows that respect and equality are the fundamental principles for maintaining friendly relationships between cultures. In Qinghai we find several examples of respect towards other cultures. Since religion is the most sacred core value, requiring the most respect, the respect demonstrated for the others by each ethnic group in Qinghai is very praiseworthy. The two examples provided below are well-known stories in this area.

At the centre of the main hall of the Dongguan Great Mosque of Xining there are three gold-plated cylinders. It is said that these three cylinders were a gift from the Jiamuyang living Buddha upon the completion of the Great Mosque, transported by monks on yaks from Labrang monastery in Xiahe, Gansu, to Xining. Not only that, but when the minaret of this mosque was completed, the abbot and monks of Kumbum monastery attended the inauguration ceremony, bringing precious gifts to express their congratulations. This is a vivid example of the respect of Tibetan Buddhism towards Islam.

After the Great Mosque underwent further renovations, it required a tall timber pole. People knew that the Fan Family, by the tomb of Shengfangou (now called Yinshenggou) in Ledu county, not far from Xining, had a huge tree, and the local leading figure of the engineering project, Ma Qi, sent an aide-de-camp to negotiate. The Fan Family believed that: "Whether it is the Hui people or the Han people who are building temples, it is always a good deed." Thus, they agreed to offer the timber. When Ma Qi received the news, he sent a group of representatives to deliver silver as an expression of gratitude. This story is a reminder of the friendship of the Han people and reflects the attitude of Han culture towards Islamic culture.

\section{Discussion}

On the basis of the ethnic cultures in Qinghai, we can further discuss the connotation of "harmony in diversity" in the relationship between ethnic groups. 
The connotation of "diversity"

"Diversity" refers to variegation and difference between the thousands of things that exist in the world, and with regards to ethnic cultures, it indicates a variety of ethnic cultures, each with their own features. Within the structure of "pluralistic integration" between the different Chinese nationalities, it indicates the pluralistic aspect, namely that each ethnic group has a stable identity and important cultural traits that are also respected by other people.

\section{The connotation of "harmony"}

"Harmony" is a concept of dynamic balance. Generally speaking, it refers to things that are different in nature coexisting at the same time, each thriving on its own, each in the correct place, in order to achieve balance and unity, embodying the spirit of "nourishing a myriad things growing up without harming each other, and following their course simultaneously without interfering with each other" in traditional culture. What "harmony in diversity" embodies are the feelings of cultural tolerance and cultural sharing.

So, when it comes to the experience in Qinghai, what is the context of "harmony"?

\section{Different cultures mutually learning from and respecting each other}

First of all, there are different cultures learning from each other. Culturally speaking, the attitude of different ethnic groups in Qinghai is very open, and there are numerous examples of different cultural factors being reciprocally borrowed. Secondly, there is mutual respect between cultures. This is interrelated with the issue of the significant concept of "cultural focus," raised by Lin Dun et al., as part of the theory of acculturation. The so-called cultural focus indicates the core factors of a culture that can be the most representative elements of said culture. Regardless of what they come in contact with, how they are mixed, these core factors remain unvaried. The core of an ethnic culture, such as religion and ethnic identity, are deep-rooted customs dating back thousands of years, they are ingrained and are difficult to change, and are also difficult to share with other ethnic groups. For this, mutual respect is needed. The experience of Qinghai indicates that in terms of culture, what can be shared is shared, and what cannot be shared is respected, such that different cultures are "linked with each other, having their own distinguishing features, respecting differences, and tolerating pluralism." This is an important principle for the long-term amicable interactions between different ethnic cultures in Qinghai.

\section{The shaping of an ethnic multi-identity}

The ethnic identity we have talked about here is part of social identity. Social identity is the self-awareness of a social community, where "us" is understood as being different from "them," and embodies the beliefs, values and behaviour orientation 
shared by the members of a society, including a sense of belonging and heart-felt commitment that the individuals have towards their own community and culture.

A multi-identity is a common phenomenon within an identity. When it comes to individual identity, as someone living within a society, a person has multiple social identities, like man, son, husband, father, Chinese person, worker, et cetera. He has formed a multi-identity towards these multiple social identities. It is the same for a social community. As an example of the multi-identity of an ethnic group, the Tibetan group identifies itself first and foremost as Tibetan, but it can also identify itself as a member of the Chinese people. Fei Xiaotong proposed the multi-leveled theory of ethnic identity consciousness regarding the multi-identity of ethnic groups. In his view, all the components belonging to Chinese nationality have an ethnic identity consciousness at a higher level, which consists of the feelings and morality of shared joys and sorrows, shared existence and death, shared honours and disgraces, and a shared destiny. The identity as a Chinese is the identity at the higher level, while the identity as being part of an ethnicity is at a lower level. With this he implied that identities of different levels can coexist without being conflicting (Xiaotong 1999).

In Qinghai we have seen how each ethnicity has multiple ethnic identities. Other than the identity of their own ethnicity, they also have the identification with the Chinese people, the motherland, and the central government. The ethnic identities of the main six nationalities in Qinghai, that is Tibetan, Mongolian, Hui, Tu, Salar and Han, are all part of the family of the Chinese nationality, and they consider the Qinghai-Tibetan plateau and the Hehuang valley they have inhabited for generations to be an organic, inalienable part of the Chinese motherland. For example, the Tibetans used to call the emperor "gongmajiawo", which means emperor of the central dynasty, and can be translated as paramount, supreme. Another example is an ancient Tibetan proverb that goes, "When the emperor's position is unstable, the common people are also restless." The third instance is the story that all Chinese people have heard since they were little kids: the emperor is the son of heaven, and the son of heaven is the monarch of the human world. Therefore, every year on Chinese New Year's Eve, he would kowtow towards all directions, and on this night Tibetan families stayed awake, waiting for the emperor to kowtow, and they would all kowtow at the same time, waking even their sleeping elders and children to do the same. Thus, this story went from idea to action. This is the biggest identity of the Tibetan people towards the nation.

First of all, throughout history they have considered the emperor of the central dynasty as their secular leader, and in some temples the emperor and Buddhist deities were venerated at the same time. Secondly, when the people of China were affected by calamities, the people and religious leaders of Qinghai would express their patriotic spirit by sharing a bitter hatred against a common threat. In 1937, the Japanese invaders started a total invasion of China, and people in Qinghai reacted with the same hatred as the soldiers and civilians all over the country, and in a very short period of time, the Qinghai People's Resistance Reinforcement, the Qinghai division for National General Mobilisation, the Xining Academic Student Union, Women Union, Worker's Union, and Business Union were established to resist the Japanese invasion. These groups put a lot of effort in spreading the importance of the war of resistance, launching activities for donating money and goods, and credit checking. At 
the same time, religious leaders also actively participated in the propaganda campaigns against the Japanese aggression. In 1939, individuals like Tibetan great master and patriot Xirao Jiacuo and scholar Yang Zhifu were appointed by the Mongolian and Tibetan committee of the Guomindang government, going to monasteries in areas inhabited by Mongols and Tibetans to carry out propaganda activities against the Japanese aggression. In the same year, the Mongolian personnel from Qinghai stationed in Nanjing selected a few representatives to carry out propaganda among the Mongolians living in Qinghai.

Once again, after the Reform and Opening-up era, the sense of national identity of the people in Qinghai, as well as their ethnic pride in being part of the Chinese people grew stronger. While talking with members of the management and the common people of the mosque in Qiaotou township, Datong county, they did not avoid the topics like the Iraqi war or terrorism. They said they realized the correctness of the party's policies on ethnic religion and the importance of stablility and unity, and "optimal situations do not come easily, they should be treasured." Furthermore, they also acknowledged that if the Chinese people want to avoid being taken advantage of, they need to be strong. These instances fully embody the endorsement and loyalty of the people in Qinghai towards their country.

Multi-identities are comprised of many things. Apart from multi-identity in terms of ethnicity, there also are other identities that go beyond the identity of that ethnic group, such as the identity of a community living in a certain region. When ethnic groups live together, and people from different ethnicities cohabitate in the same region for a long time, a regional community is formed: the identity of this community for people living in that region is based on factors related to the territory, such as the natural environment, historical anecdotes, and cultural heroes, and obviously, it also includes common interests. The same type of identity exists within the ethnic groups in Qinghai.

This kind of territorial identity of different ethnic groups is further developed in the interactions between individuals. In Zhuocang, people make friends with individuals from different ethnic groups, and many people become sworn brothers or godparents, and when they make an oath of alliance, those people are considered relatives for life, so much so that this relationship is extended to the second and third generations.

\section{The mechanisms of rationally resolving conflicts}

When different ethnicities live together, conflicts often arise for all sorts of reasons. The problem here is not whether or not conflicts arise, but if there are mechanisms in place to rationally solve them. In Qinghai, there is such a mechanism. It involves both institutional mechanisms put in place by the central governments, as well as the mechanism of popular conventions. Historically the two lifestyles of nomadic pastoralism and agriculture both existed in Qinghai, and at times conflicts would arise between the two sides. However, these did not result in a circle of hate, but in hate being resolved through harmony. From the inscriptions like the one on the Kumbum "Documentary" Stele in Kumbum monastery (dated in April of the 9th year of Qianlong's reign), we can see the conflicts between farmers and shepherds. 
In traditional society, social customs are the main force of integration for a community (Giddens 1998). If the authorities were not disturbed, traditionally the people all around Qinghai had rules in the context of the village for resolving these conflicts. These rules accumulated through an historical process of rationalisation of popular wisdom, playing an important role in the regulation of social life and the settlement of conflicts. In Qinghai, because of territorial disputes or episodes of bloodshed between Mongols and Tibetans, if the blame mainly lay on the Tibetan side, the elders of the tribe involved would send a prestigious Living Buddha, who would bring gold, silver and cattle, and offer a khata and tea,he would meet with the elders of the Mongolian tribe to intercede, make amends, and compensate for their loss, asking for their forgiveness. The same would happen if the blame was on the Mongolians.

Forming the conditions of harmony in diversity

\section{Cohabitation of ethnic groups in the same territory}

As we have already said, when different ethnicities live together for a long time, with frequent contacts, they form a common consciousness and common interests linked with the territory. This is a condition for shaping an identity at a higher level.

\section{A multi-ethnic unified country at the political level}

The long-term existence of a multi-ethnic state founded together by multiple nationalities, together with effective governance, constitutes the fundamental political security of multi-ethnic "harmony in diversity." It constantly promotes the centripetal force and cohesion of the Chinese people, contributing to the creation of national blood where different nationalities live in symbiosis and thrive.

\section{Complementing each other on an economic level}

The Han people living in Qinghai mainly engaged in agricultural production, while the Tibetans and Mongolians practiced animal husbandry and forestry; finally, the Hui and Salar people mostly carried out trade activities. On an economic level they benefited from each other, they were inevitably linked to one another: these complementary relationships favoured peaceful ethnic relations. ${ }^{16}$

\section{Cultural factors}

Firstly, Qinghai is located in a marginal area where different cultural spheres meet. Basic anthropological theories tell us that in multi-cultural territories acculturation can take place easily. Qinghai is situated at the intersection of the Tibetan, Han, and Islamic cultural spheres: these cultures collided and blended over a long period of time, forming an extremely intricate system of reciprocal relations. This is why nowadays we see such diverse phenomena of acculturation. 
Secondly, each representative culture in Qinghai has elements connecting them to each other. The fundamental values and objectives of Confucianism are humanity, righteousness, propriety, wisdom, and faithfulness. The basic values of Tibetan Buddhism are "refrain from doing any evil and pursue everything that is virtuous," as well as the ideals of leniency, mercifulness, enlightenment, good conduct, living in mindfultness of the afterlife, and yearning for Buddha. The core values of Islam are "performing charity, aiding the poor, upholding virtue and condemning evil, pursuing happiness in this life and in the afterlife," and so on. In short, the human virtues of "doing good deeds and giving to charity" are universally advocated values, as well as value orientations common to different ethnic cultures. Because of this, while preserving their own cultural core, different cultures also create a structure of ethnic cultures where commonality does not harm the differences, differences do not harm the commonality.

\section{Result and conclusion}

The question of how to realise harmonious ethnic relationships in a multi-ethnic state is assiduously explored by politicians and scholars in many countries. We have witnessed far too many tragedies of ethnic tensions becoming politicised, or ethnic massacres that happened because of the intervention of international politics, and even civil war. China is multi-ethnic with a rich, harmonious cultural tradition, and its ethnic cultures form a complex of entities infiltrating each other through pluralistic combination, coexistence of diversity, and multipolar interaction. This has determined the multiplicity of its people's identity, as well as the complexity of acculturation. This vital source and flowing process of Chinese ethnic cultures has enabled it to form a structure characterised by "harmony in diversity," "seeking common ground while reserving differences," and "pluralistic integration" in which "everybody goes in the same direction in different ways, and everybody thinks as one," where they "are unified but maintaining their differences, and are consistent with each other despite these differences," and "use different means to obtain the same result."

Ethnic cultures in Qinghai paint a picture on a smaller scale of ethnic cultures in China, and in this smaller space, materially and spiritually self-sufficient, it is a natural concentrate, a high-level condensation and a very representative miniature version of the cultures of the Chinese nationalities. The cultural identity models of

\footnotetext{
${ }^{16}$ The author's hometown is located in Qunjia Tibetan township of Huangzhong county, Qinghai province, surrounded by a primeval forest. During the Cultural Revolution, the Qunjia Tibetans experienced a shortage of grain. On the other hand, many Han people living on the other side of the mountain in Huangzhong county had grains, but no forest, thus they lacked timber to make tools. The Qunjia Tibetans built wooden manufacturing tools and household items, and traded them with the Han people. Thanks to the honesty of both the Han and the Tibetan villages, they made fair deals, and everybody established friendships. Every Tibetan family in my hometown has Han friends, whom they call "jiaxia" in Tibetan, meaning Han friend. After transporting the goods across the mountains to the community inhabited by the Han, the Tibetans stay in the homes of the "jiaxia" and when the "jiaxia" go to their [the Tibetans'] hometown, they would stay at their Tibetan friends' homes. Once they finished trading goods, they would go to their friends' homes to eat meat, drink wine, and chat, as if they were one big family.
} 
the people in Qinghai indicate that "harmony in diversity" is a noumenal, historical fact that formed and developed in each ethnic culture in China, as a habit of the Chinese people, or a "materialised" historical legacy, and is part of their code of conduct, a practical behaviour common to people from all ethnic groups since ancient times, and it also is an ideal state pursued by all Chinese people. Overall, "harmony in diversity" is a form of practical rationality in which the four dimensions of noumenal historical fact, ideology, behaviour and the ideal realm form an integral whole. It also proves that in a multi-ethnic culture "harmony creates new substances, while sameness causes decay." The members of the Communist Party of China founded an ethnic theory with Chinese ethnic characteristics, in accordance with Marxist ethnic theory and the historical form of Chinese ethnic cultures, thus taking the concept of "harmony in diversity" from "unrestrained" to "conscious." After the founding of the People's Republic of China, they systematically formulated new ethnic policies, therefore systematising the concept of "harmony in diversity" and ensuring the safety and development of all ethnic groups and their cultures within a national framework and in the context of policies. Consequently, the ethnic theory and ethnic policies of the Communist Party of China and the idea of "harmony in diversity" share a common origin, as well as a relationship that continues through time. We firmly believe that with the advancement of constructing a harmonious society, we can increasingly enrich the connotation of "harmony in diversity," and in the future it may blossom in an even more spending flower within the practice of socialism with Chinese characteristics. For a long time "harmony in diversity" has represented the condensation of the ideological wisdom, political wisdom and life wisdom of the Chinese people, it is one of our established customs, viewed as an iron principle, as well as valuable spiritual wealth that we devote to ethnic groups around the world.

\section{Availability of data and materials}

Please contact author for data requests.

\section{Authors' contributions}

The author carried out the fieldwork and investigations, and wrote the overall article. The author read and approved the final manuscript.

\section{Ethics approval and consent to participate}

All the participants of this research are in accordance with the research ethical principles. I have gathered the necessary information officially and legally on the multi-ethnic cultures in Qinghai. No animals are involved in this research. Therefore, I want to approve that there is no mistake concerning the necessary ethical consideration.

\section{Competing interests}

The author declares that he/she has no competing interests. 


\section{Publisher's Note}

Springer Nature remains neutral with regard to jurisdictional claims in published maps and institutional affiliations.

\section{References}

Giddens, Anthony. 1998. The nation-state and violence, 230. Beijing: Joint Publishing Chinese edition translated by Hu Zong et al.

Hangxiudongzhu, Garang, and Garang Shangmajie. 2002a. A study of the origin of the Zhuocang Tibetans, 194. Beijing: Qinghai Ethnic Publishing House.

Hangxiudongzhu, Garang, and Garang Shangmajie. 2002b. A study of the origin of the Zhuocang Tibetans, 194. Qinghai Ethnic Publishing House.

Kongshao, Zhuang, ed. 2005. A general theory of anthropology, 356. Shanxi Education Press.

Rang, Cai. 1999. Faith and popular customs of Tibetan Buddhism, 119-120. Beijing: The Ethnic Publishing House.

Xiaotong, Fei, ed. 1999. The Pluralistic Unity of the Chinese Nation (revised edition), 13. Beijing: Minzu University of China Press.

Xiaotong, Fei. 2005. Building a global Society of Harmony in diversity. In Ninety new speeches, 114. Beijing: Chongqing Publishing Group.

Youlan, Feng. 1999. A history of Chinese modern philosophy, 253. Beijing: Guangdong People's Publishing House. 